\title{
Ações extensionistas de promoção da saúde bucal em comunidades atendidas pela Pastoral da Criança em Londrina/PR
}

\author{
Lucas Fernando Oliveira Tomaz Ferraresso*; Sabrina Santana Cassemiro*; Lirian Adriana Maria \\ Pereira da Silva**; Maura Sassahara Higasi***; Maria Luiza Hiromi Iwakura Kasai***; Helion Leão \\ Lino Junior***; Wagner José Silva Ursi*****
}

* Graduando(a) em Odontologia, Universidade Estadual de Londrina

** Técnica em Saúde Bucal, Universidade Estadual de Londrina

*** Docente, Departamento de Medicina Oral e Odontologia Infantil, Universidade Estadual de Londrina

**** Docente, Departamento de Odontologia Restauradora, Universidade Estadual de Londrina

Recebido: 09/04/2021. Aprovado: 12/09/2021.

\begin{abstract}
RESUMO
Trata-se de um estudo de caráter descritivo, do tipo relato de experiência, que tem por objetivo descrever as ações extensionistas desenvolvidas pelo projeto "Saúde Bucal em Escolares e a Comunidade" da Universidade Estadual de Londrina em Pastoral da Criança. Essas atividades foram desenvolvidas no ano de 2019, aos sábados, em datas previamente definidas pelas coordenadoras das próprias instituições. Num primeiro momento foram realizadas rodas de conversa com as mães, gestantes e cuidadores, com temáticas referentes ao rico valor do aleitamento materno, esclarecimentos sobre o uso de chupetas e alimentação saudável. Num momento posterior, sob a supervisão dos responsáveis, foi efetuada a higienização da cavidade bucal dos bebês. Para as crianças, foi executada a escovação supervisionada individual ou coletiva. Além disso, foram compartilhadas informações referentes à técnica de escovação correta, frequência de escovação ao dia e quantidade ideal de dentifrício. Essas ações contaram com a participação de gestantes, mães, cuidadores, bebês e crianças, totalizando cerca de 1241 pessoas em 19 comunidades assistidas pela Pastoral da Criança, localizadas em Londrina/PR. Dessa forma, as ações extensionistas em Pastoral da Criança revelaram-se cenários oportunos para compartilhar saberes, intercambiar experiências, melhorar a qualidade de vida e bem-estar dos diversos e heterogêneos públicos-alvo. Representaram espaços reais e favoráveis para os estudantes desenvolverem competências e habilidades requisitadas para a formação contextualizada e integral.
\end{abstract}

Descritores: Saúde Bucal. Educação em Saúde. Promoção da Saúde.

\section{INTRODUÇÃO}

A formação do ensino superior tem a proposta de articular ensino, pesquisa e extensão, e os projetos extensionistas buscam aproximar universidade e comunidade. Desse modo, o objetivo deste estudo é relatar as contribuições de um projeto de extensão da Universidade Estadual de Londrina (UEL), por meio de um relato de experiência das ações extensionistas desenvolvidas em comunidades atendidas pela Pastoral da Criança no município de Londrina/PR.

Pastoral da Criança é um organismo de ação 
social da Conferência Nacional dos Bispos do Brasil que promove o desenvolvimento de crianças, preferencialmente menos favorecidas, desde o nascimento até os 6 anos de idade, cujo objetivo é o cuidado integral das crianças por meio de orientações básicas de saúde, nutrição, educação e cidadania, promovendo o desenvolvimento de suas famílias e comunidades ${ }^{1}$. Foi fundada em 1983 em Florestópolis-PR, como proposta da Igreja Católica Apostólica Romana no Brasil e da médica Zilda Arns, para combater a desnutrição e taxa de mortalidade infantil (TMI) ${ }^{2,3}$. Na época, a TMI no Brasil, era de 90 crianças a cada 1000 nascidos vivos ${ }^{4}$ e 127 em Florestópolis ${ }^{5}$. A atuação da Pastoral da Criança em Florestópolis promoveu a diminuição da TMI para 28 mortes por mil crianças nascidas vivas ${ }^{5,6}$.

Atuando em toda a extensão do país, a Pastoral da Criança conseguiu avançar e atingir seus objetivos graças ao trabalho de voluntários, que atualmente são de mais de 160 mil, dos quais 87.671 são líderes comunitários que acompanham quase um milhão de crianças e 55 mil gestantes em 781 famílias $^{7}$. As principais atividades realizadas pelos líderes são visitas domiciliares para acompanhamento das famílias, realização do dia da vigilância nutricional, reuniões com as famílias, articulação com o sistema de saúde e com outras pastorais, e registro do desenvolvimento das crianças e das gestantes ${ }^{8}$. Estes líderes possuem o compromisso de multiplicar saberes e disseminar informações seguras a toda a comunidade, principalmente às gestantes e crianças ${ }^{9}$. Nesse sentido, trabalhar as vertentes de saúde com esses grupos, incentiva e promove o desenvolvimento de hábitos benéficos à saúde geral e bucal, favorecendo assim o seu aprendizado e de seu núcleo familiar.

Nessa perspectiva, a Pastoral da Criança adotou a saúde bucal como parte das ações básicas destinadas às crianças e pais ${ }^{10}$, pois o cuidado na primeira infância representa uma nova compreensão centrada em prevenir e promover saúde ${ }^{11}$, visto que a cárie dentária é uma doença que ainda está presente em $50 \%$ das crianças $^{12}$. A atuação anterior ao estabelecimento da doença cárie dentária pode ser realizada por meio de troca de saberes entre as instituições de ensino superior (IES) e Pastoral da Criança, promovendo saúde junto à comunidade, oportunizando a adoção e o enraizamento de hábitos bucais desde a mais tenra idade, bem como a redução e prevenção desta doença. O caminho para esse vínculo entre IES e comunidade acontece por meio de ações extensionistas (AE) que possibilitam a imersão e aprofundamento dos cuidados para com a população e o reforço do compromisso social das IES. As AE mostram-se importantes estratégias para promover ofertas de ações de saúde ${ }^{13}$, construção da autonomia e fortalecimento identitário da comunidade ${ }^{14}$.

É fato que as AE são instrumentos relevantes para o processo individual e coletivo de formação acadêmica, que não se limita ao tradicional, uma vez que, contribui para formação em saúde mais humanista, generalista e preparado para atuar frente à situação de saúde do país ${ }^{15}$. Trabalhar em ambientes extramurais como em comunidades atendidas pela Pastoral, oportuniza o elo entre IES e comunidade, transformando o meio no qual estão contextualizadas de forma compartilhada, eficaz e dialógica. A Pastoral da Criança configura-se oportunidade ímpar para o aperfeiçoamento e o desenvolvimento de competências e habilidades requisitadas pelas Diretrizes Curriculares Nacionais. É esse ambiente que favorece o aprender a aprender, aprender a ser e aprender a pensar ${ }^{16}$.

\section{RELATO DE EXPERIÊNCIA}

\section{Proposta geral e delineamento metodológico}

Trata-se de um estudo descritivo, do tipo relato de experiência, referente às $\mathrm{AE}$ em comunidades atendidas pela Pastoral da Criança do 
projeto de extensão "Saúde Bucal em Escolares e a Comunidade" da UEL. Atualmente, esse projeto é vinculado aos Departamentos de Medicina Oral e Odontologia Infantil, além da parceria com a Secretaria Municipal de Saúde de Londrina por intermédio da Gerência de Odontologia, vinculada à Diretoria de Atenção Primária à Saúde. Todas as etapas acerca da metodologia adotada para o desenvolvimento e realização das ações extensionistas estão descritas na figura 1 .

No início do último ano de execução, o projeto contou com a participação de uma Técnica em Saúde Bucal, quatro docentes do curso e selecionou 39 estudantes, do $1^{\circ}$ ao $5^{\circ}$ ano do curso de Odontologia. Todos os estudantes participantes foram devidamente orientados pelos docentes no início do ano letivo sobre as possíveis temáticas que poderiam surgir como demandas das comunidades vinculadas à Pastoral da Criança. Além disso, foram devidamente capacitados para realizarem práticas de instrução de higiene bucal para bebês e crianças (figura 2).

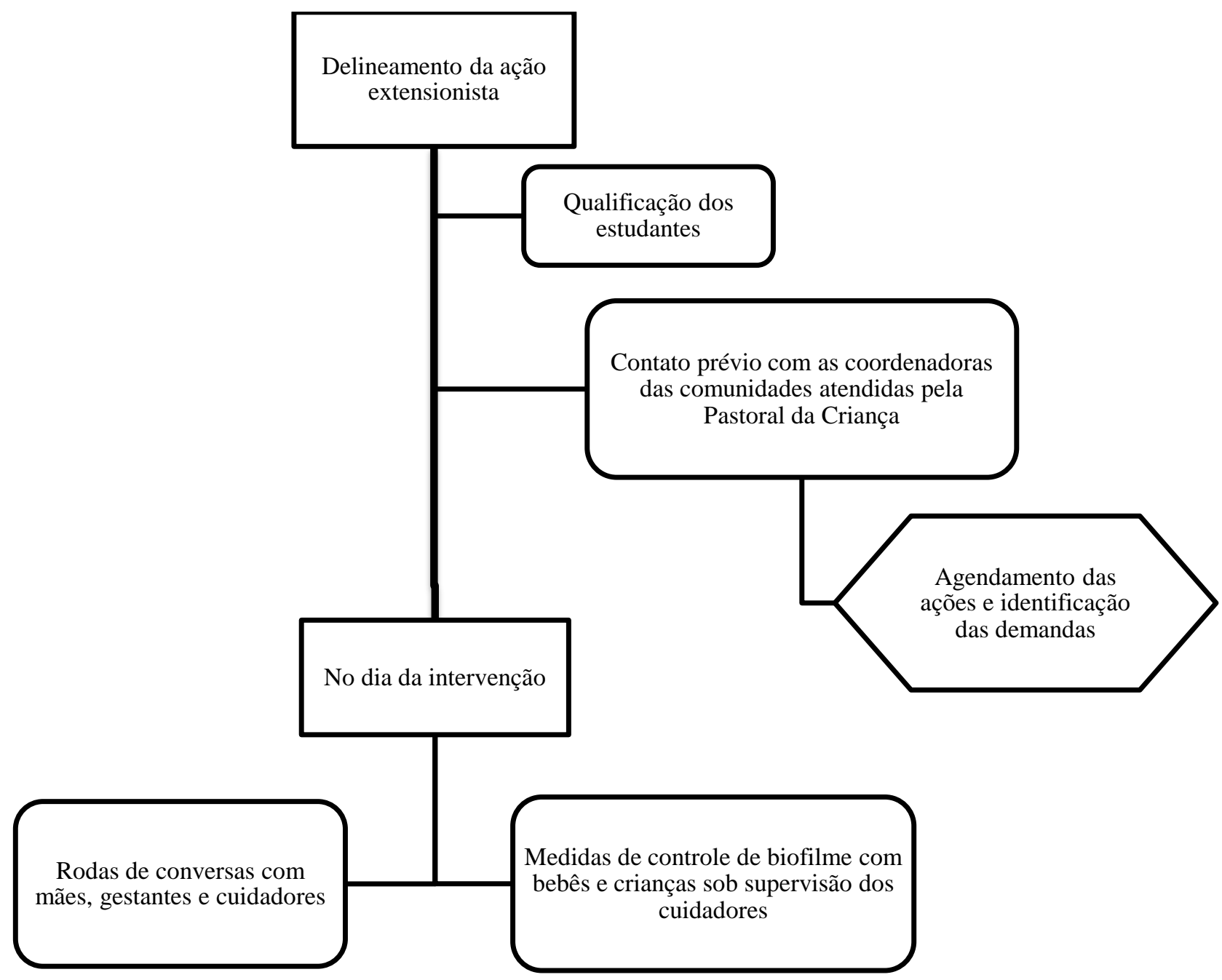

Figura 1. Etapas para o desenvolvimento da ação extensionista 


\begin{tabular}{|c|c|c|}
\hline Temáticas abordadas com os estudantes & Públicos-alvo & Intencionalidades \\
\hline $\begin{array}{l}\text { Recomendações de manejo comportamental } \\
\text { infantil }\end{array}$ & Estudantes & Facilitar o trabalho com bebês e crianças \\
\hline Alimentação saudável do bebê e da criança & Bebês e crianças & $\begin{array}{l}\text { Incorporação de hábitos alimentares } \\
\text { saudáveis }\end{array}$ \\
\hline Cuidados com a higiene bucal dos bebês & Bebês & $\begin{array}{l}\text { Promoção de saúde e práticas positivas em } \\
\text { saúde bucal }\end{array}$ \\
\hline $\begin{array}{l}\text { Escovação dentária supervisionada para as } \\
\text { crianças }\end{array}$ & Crianças & $\begin{array}{l}\text { Promoção de saúde e práticas positivas em } \\
\text { saúde bucal }\end{array}$ \\
\hline $\begin{array}{l}\text { Fatores de risco para o desenvolvimento de } \\
\text { cárie dentária e outras doenças bucais }\end{array}$ & $\begin{array}{l}\text { Crianças e } \\
\text { cuidadores }\end{array}$ & $\begin{array}{l}\text { Promoção de saúde e compreensão sobre os } \\
\text { fatores de risco }\end{array}$ \\
\hline Uso de chupetas e mamadeiras & $\begin{array}{l}\text { Bebês, crianças e } \\
\text { cuidadores }\end{array}$ & $\begin{array}{l}\text { Promoção de saúde e compartilhamento de } \\
\text { saberes }\end{array}$ \\
\hline Assistência odontológica à gestante & Gestantes e mães & $\begin{array}{l}\text { Promoção de saúde, compartilhamento de } \\
\text { saberes e desconstrução de mitos }\end{array}$ \\
\hline Aleitamento materno e saúde bucal & $\begin{array}{l}\text { Gestantes, mães e } \\
\text { cuidadores }\end{array}$ & Promoção de saúde e incentivos \\
\hline Traumatismo dento-alveolar & $\begin{array}{l}\text { Gestantes, mães e } \\
\text { cuidadores }\end{array}$ & Como agir caso aconteça \\
\hline
\end{tabular}

Figura 2. Qualificação dos estudantes previamente ao desenvolvimento das ações extensionistas

Para a condução de cada intervenção, a Técnica em Saúde Bucal foi responsável pelo contato prévio com as coordenadoras das comunidades atendidas pela Pastoral da Criança. Neste momento, foram definidos os sábados para realização das atividades e identificadas as demandas e prioridades apresentadas pelas coordenadoras. Caso alguma demanda não tivesse sido contemplada durante a qualificação estudantil, novas orientações deveriam obrigatoriamente ser compartilhadas. De acordo com Ferraresso e Codato $(2021)^{17}$, as ações extensionistas implicam necessariamente na identificação das demandas e a ação frente à realidade. Para os autores, o enfrentamento e a resolução das demandas apresentadas pelos diferentes contextos sociais é uma missão desafiadora, exige escuta ativa, adequação e organização do trabalho ${ }^{17}$.

$\mathrm{O}$ número de atividades, a média de participantes em cada intervenção e periodicidade das ações foram descritos na tabela 1. Vale destacar que em cada intervenção em determinado local houve a presença de novos participantes da comunidade, sendo que o mesmo participante não teve a obrigatoriedade de participar dos encontros subsequentes.

\section{Rodas de conversa com a comunidade}

No início da atividade, foi realizado o acolhimento e o fortalecimento de vínculo com a população por meio de rodas de conversa, o que originou e fomentou discussões e momentos desafiadores. Buscou-se, nesse momento, que a partir da demanda previamente solicitada pela coordenadora, todos os atores compartilhassem suas situações experienciadas, dúvidas, anseios e expectativas, no intuito de direcionar a atuação com os participantes e aproximar comunidade- 
comunidade, comunidade-estudante e comunidade-docente.

Observou-se que a receptividade e adesão das gestantes, mães e responsáveis foi heterogênea. Isso se esclarece devido à pluralidade, subjetividade e o momento em que os indivíduos se encontram, requerendo a atenção e a rápida tomada de decisões para a consolidação das ações e a melhor fluidez das atividades. Sabese que ao falar o sujeito divide com os outros suas experiências e aprende a argumentar, instigando os demais participantes a novos diálogos, construindo assim um espaço de aprendizado e de troca de saberes ${ }^{18}$.

Devido à intensa participação de gestantes, mães e cuidadores, as principais demandas foram sobre aleitamento materno, uso de chupetas e alimentação saudável. Essas temáticas discutidas de forma clara, coloquial, direta e objetiva, favorecem o entendimento, a apropriação e a aplicação diária. Tema de preciosidade única, o aleitamento materno exclusivo foi debatido com as participantes destacando suas potencialidades e as fragilidades. Nossa atuação com as gestantes, mães e cuidadores foi compartilhada, com o intuito de que as informações possam somar-se e adequar-se ao cotidiano, potencializando e fortalecendo a prática do aleitamento materno. Desse modo, se fez necessário ouvir o que essas participantes tinham para nos contar, pois foi a partir dessa fala que conhecemos suas particularidades. Assim, foi destacado às integrantes, dentro de cada realidade, que até aos 6 meses, preferencialmente, o bebê deve ser nutrido exclusivamente pelo aleitamento materno, que deve ser mantido após esse período, com a introdução de alimentos saudáveis de forma complementar até 2 anos de idade ${ }^{19}$.

Por conseguinte, foi discutido com as participantes os benefícios do aleitamento materno tanto para o recém-nascido quanto para a mãe. Ressaltou-se nesse momento, que essa prática resulta em capacidade imunoprotetora, desenvolvimento de vínculos afetivos saudáveis entre mamãe e bebê, diminuição de doenças e o rico valor nutritivo e econômico ${ }^{20}$. Da mesma forma, representa uma das principais medidas protetivas contra a obesidade, visto que a associação dos hábitos alimentares dos bebês, o tempo em que recebem aleitamento materno exclusivo, juntamente ao momento que incorporam alimentos sólidos, afetam diretamente o sobrepeso e o potencial de desenvolver obesidade infantil ${ }^{21}$.

Desta forma, coube a nós como agentes promotores de saúde, estimular, aconselhar e compartilhar os inúmeros impactos positivos da amamentação a todos os envolvidos. Tal realização requereu do estudante a percepção frente às reais necessidades desses indivíduos e das respectivas famílias. Originou olhar crítico e humanizado, subsidiando cuidados e estratégias para a atenção e melhoria na qualidade de vida dos participantes.

Nessa integração, houve a oportunidade e necessidade de trabalhar aspectos referentes ao uso de chupetas, visto que a ausência de aleitamento materno nos 6 primeiros meses de vida também pode originar a inserção precoce desse hábito de sucção não nutritivo ${ }^{22}$. Além disso, o uso de chupeta favorece a interrupção precoce do aleitamento materno, interferindo no desenvolvimento das estruturas orofaciais, alterando as funções de mastigação e deglutição da criança $^{23}$. Sendo assim, apesar da intensa influência de hábitos culturais populares, nossa atuação com as mães baseou-se no encorajamento para a diminuição do uso e posterior remoção da chupeta, utilizando-se de recursos lúdicos, de forma gradual e sem castigos à criança. Para isso, o estudante foi responsável por ponderar todas as perspectivas relatadas, sendo capaz de compreender a realidade dos envolvidos e buscar soluções para os problemas 
encontrados, aliando conhecimentos científicos e o poder de resolubilidade.

Outro tema solicitado, a alimentação saudável da criança, ainda representa um desafio, em função dos pais e cuidadores serem os principais encarregados por tal tarefa, necessitando atenção e esforços especiais. Notamos durante a atividade, relatos da introdução precoce de açúcar e maior acesso das crianças a esses alimentos. Nesse sentido, essa acessibilidade e prematura inserção acontecem advindas da tentativa dos pais e cuidadores de demonstrarem afeto, amor e gratificação à criança, instalando assim, uma preferência indevida pelo sabor. Consequentemente, a introdução e consumo precoce do açúcar na dieta das crianças, antes dos seis meses de idade, representa risco ao seu desenvolvimento e favorece a ocorrência de cárie dentária ${ }^{24,25}$.

Diante disso, nossa conduta objetivou conscientizar os pais e cuidadores para a prevenção dessa doença, mantendo a alimentação saudável e o poder limitativo ao consumo de alimentos cariogênicos. Para tal, foi aconselhado que para bebês não seja introduzido nenhum tipo de alimento açucarado ${ }^{26}$, dando preferência à introdução de frutas, verduras e legumes. Já para as crianças acima de 2 anos, os pais foram orientados a serem restritivos em relação à frequência da ingestão de doces, evitando lugares de fácil visualização pelas crianças.

Nessa lógica, trabalhar rodas de conversa em comunidades atendidas pela Pastoral da Criança, nesse período tão precioso na vida da mulher, estimulou o diálogo, a escuta qualificada e a potencialização dos saberes. A participação da equipe tranquilizou e motivou gestantes e mães, tornando-as mais seguras quanto às melhores condutas e ampliando a compreensão sobre saúde. As orientações compartilhadas estimularam novos questionamentos e debates, o que é favorável para adoção de hábitos e práticas positivas em saúde. A ação demandou dos estudantes senso crítico, tomada de decisão e abordagem efetiva que resultasse em esclarecimentos verdadeiros.

Trabalhar educação em saúde instiga mudanças no modo de vida e comportamento da comunidade $^{27}$, gera benefícios bilaterais e sinergia para o alcance de avanços no cuidado da população ${ }^{28}$. Requer exigências envolvendo inteligência emocional e relações interpessoais, que possam tornar os profissionais sempre aptos a atuarem de maneira a garantir a integralidade dos cuidados $^{29}$.

\section{Medidas de controle de biofilme dentário}

Após o acolhimento e interação com a população, foram realizadas medidas de controle de biofilme, visto que é o principal fator para desenvolvimento de doenças que afetam dentes e tecidos periodontais ${ }^{30}$. As ações preventivas realizadas pelo projeto de extensão foram a evidenciação de biofilme dentário e escovação supervisionada individual e coletiva. A evidenciação de biofilme foi usada como agente motivacional, por ser algo que a criança pode visualizar, facilitando o seu aprendizado. Assim, as crianças puderam observar as regiões que mais acumulavam biofilme com o uso de espelho. A evidenciação é um recurso lúdico que propiciou um procedimento habitual de forma mais leve, viabilizando compartilhar a importância da escovação e da remoção do biofilme ${ }^{31}$.

Em seguida foi distribuído um kit de higiene bucal, composto por uma escova de dente e um dentifrício fluoretado, e as crianças foram orientadas a remover corretamente o biofilme dentário por meio da escovação supervisionada. A técnica de escovação utilizada para as crianças em idades pré-escolares foi a de Fones, por ser mais simples e de fácil execução, o que auxilia na memorização dos passos desta técnica ${ }^{32}$.

Em crianças com menos de cinco anos e 
com pouca coordenação motora, a escovação foi efetuada individualmente e com supervisão dos estudantes, porém depois eles foram estimulados a escovar sozinhos para que treinassem sua destreza manual. Para os bebês que ainda não possuíam dentes, a higienização da cavidade bucal foi executada com gaze estéril, enrolada no dedo e embebida com água filtrada ${ }^{33}$. A higienização da cavidade bucal do bebê tem o objetivo de remover os restos alimentares e criar o hábito da limpeza, além de familiarizar o bebê com a manipulação da sua cavidade bucal ${ }^{34}$.

A escovação foi realizada de forma coletiva a partir dos cinco anos de idade, pois as crianças já eram maiores e já possuíam destreza manual para realizar sozinhos a escovação, e houve a interferência dos estudantes individualmente, caso fosse necessária alguma correção. Foram utilizados recursos visuais como macromodelos e fantoches para ilustrar os passos da higienização bucal. Em seguida, os estudantes do projeto serviram de modelo, para que as crianças, ao verem eles fazendo a sequência da escovação, repetissem em sua boca.

A escovação foi feita com escova dentária e dentifrício fluoretado, pois o flúor presente nos dentifrícios é benéfico para a saúde bucal devido a sua ação na prevenção da cárie dentária ${ }^{35}$. Foi necessária a orientação dos participantes quanto à quantidade de dentifrício a ser colocada na escova, sendo preconizada para os bebês a quantidade equivalente ao tamanho de um "grão de arroz cru", para a faixa etária de 3 a 5 anos o tamanho de "uma ervilha" e partir dos 6 anos, foi usada a técnica transversal ${ }^{36}$.

Outro ponto importante, é a quantidade de vezes que deve ser realizada a higienização bucal. A escovação em bebês e crianças deve ser realizada no mínimo duas vezes ao dia, sendo recomendado três vezes ${ }^{37}$. A higienização noturna é a mais importante, pois durante a noite o fluxo salivar diminui ${ }^{38}$ e a saliva tem as funções de inibir a desmineralização e auxiliar na remineralização, portanto, sua diminuição aumenta de maneira significativa o risco de cárie ${ }^{35}$.

No projeto, foi orientado que a escovação seja realizada no mínimo três vezes ao dia, visto que as crianças possuem dificuldade de realizar eficiente escovação. Por isso, foi necessário que as orientações fossem compartilhadas também para seus responsáveis, que devem realizar a higiene bucal da criança até que ela já tenha desenvolvido a habilidade motora necessária, e após isso, deve supervisionar, motivar e complementar a higienização até que ela complete 10 anos de idade. Em função disso, os pais estavam presentes durante todas as atividades, principalmente na higienização da cavidade bucal dos bebês ${ }^{39}$.

A atuação nas ações de educação em saúde permitiu o intercâmbio de conhecimentos, articulando o saber científico e o saber popular. Essa aproximação entre os estudantes e a comunidade, proporcionou a sensibilidade social e o estímulo para a transformação social. Além disso, permitiu aos participantes aderirem às ações propostas e a atuação compartilhada e dialógica entre todos os atores envolvidos.

Pode-se observar que as crianças e mães se manifestaram interessadas e motivadas com o cuidado com a higiene bucal, compreendendo o significado da atividade e realizando-a de forma adequada e com atenção. A atuação do projeto possibilitou familiarizar as crianças com os profissionais da saúde e, para as mães, compreender o papel promotor de saúde para os filhos.

Nessa AE, percebemos também que o simples gesto de distribuição do kit de higiene bucal foi transformado em um momento de valorização e atenção para a comunidade. Tal percepção possibilitou aos participantes uma atividade contextualizada para além de 
informações compartilhadas, viabilizando o entendimento de uma abordagem voltada para o cuidado, a melhora da qualidade de vida e a transformação do indivíduo para o reconhecimento de sua saúde.

Constatou-se ainda por meio de relatos que a atuação dos integrantes do projeto, e o consequente conhecimento compartilhado, favoreceu o aumento da procura aos serviços de saúde, em especial do núcleo da Odontologia. Assim sendo, acreditamos que a presença do projeto, permitiu reflexões nos indivíduos acerca do cuidado com à saúde, o seu empoderamento e o preenchimento de lacunas informacionais.

\section{CONSIDERAÇÕES FINAIS}

A metodologia de roda de conversa revelouse poderoso instrumento para envolver a comunidade e fortalecer práticas positivas em saúde de forma compartilhada, acolhedora, interativa e vinculada a mudanças no cotidiano dos indivíduos. Nesse sentido, a participação em roda de conversa representou relevante ferramenta para promover saúde, troca de experiências e melhorar a qualidade de vida da população.

A utilização de recursos para controlar o biofilme dentário, tais como evidenciação e escovação dentária supervisionada, representaram estratégias motivacionais, significativas e favoráveis para envolver as crianças e pais no processo saúde-doença. Constituíram-se recursos facilitadores do ensino-aprendizagem, que possibilitaram moldar atitudes e hábitos, conscientizar as crianças e são indispensáveis para estabelecer e manter boas condições bucais.

Diante disso, a atuação e vivência em ações extensionistas de promoção de saúde permitiram compartilhar saberes, despertar o valor e interesse para adoção de boas práticas em saúde e fortalecer a autonomia da comunidade. Para os estudantes, as ações em comunidades atendidas pela Pastoral da Criança foram fundamentais para a formação integrada e contextualizada, apta para atuar em cenários reais, com todas as suas potencialidades, desafios e limitações, buscando solucionar os problemas sociais contemporâneos vigentes.

\section{ABSTRACT \\ Extension actions for the promotion of oral health in communities served by the Child's Pastoral in Londrina/PR}

This is a descriptive study of the experience report type, aiming at describing the extension actions developed by Project "Oral Health in School Children and in the Community" developed by the State University of Londrina at the Child's Pastoral. The activities described herein were developed in 2019, on Saturdays, with dates previously defined by the coordinators of the institutions. In the first moment, talk sessions were held with mothers, pregnant women, and caregivers, with themes referred to the value of breastfeeding, clarifications on the use of pacifiers, and healthy eating. At a subsequent moment, the baby mouths were cleaned under supervision. For the children, individual or collective supervised brushing was performed. Additionally, information regarding the correct brushing technique, brushing frequency per day, and the ideal amount of toothpaste were provided. These actions had the participation of pregnant women, mothers, caregivers, babies, and children, totaling approximately 1241 people in 19 communities assisted by the Child's Pastoral in Londrina, Paraná. In this way, the extension actions taking place at Child's Pastoral were considered ideal scenarios to share knowledge, exchange experiences, improve the quality of life and wellbeing of the diverse and heterogeneous target audience. They represent real and favorable spaces for students to develop the competencies and skills required for contextualized and integral training.

Descriptors: Oral Health. Health Education.

Health Promotion.

\section{REFERÊNCIAS}

1. Pastoral da Criança [internet]. Estatuto da 
Pastoral da Criança [Acesso em 20 abr. 2020]. Disponível em: https://www.pastoraldacrianca.org.br/categ oria-institucional/68-estatuto.

2. Pastoral da Criança. Lições da Pastoral da Criança: entrevista com Zilda Arns Neumann. Estud Avanç. 2003; 17(48):6375.

3. Costa MT. Pensando o Brasil: discurso religioso e prática social segundo Zilda Arns. Estud Hist. 2015;28(55):151-68.

4. Szwarcwald CL, Castilho EA. Estimativas da mortalidade infantil no Brasil, década de oitenta: proposta de procedimento metodológico. Rev Saúde Públ. 1995;29(6):451-62.

5. Costa MOE. Corpos, cruzes e ressurreições: um estudo fenomenológico das experiências do cotidiano de mulheres líderes da Pastoral da Criança. São Cristóvão. Dissertação [Mestrado em Ciências da Religião] Universidade Federal de Sergipe; 2017.

6. Pastoral da Criança [homepage na internet]. Promovendo a vida plena para todas as crianças [Acesso em 20 abr. 2020]. Disponível em: https://www.pastoral dacrianca.org.br/images/stories/pdf/JornalA brangencia2008.pdf.

7. Pastoral da Criança [homepage na internet]. Voluntariado: benefício para todos! [Acesso em 20 abr. 2020]. Disponível em: https://www.pastoraldacriança.org.br/institu icional/voluntariado-beneficio-para-todos.

8. Carvalho VD, Souza W. Pobres no ter, ricos no ser: trabalho voluntário e motivação na Pastoral da Criança. Rev Adm Contemp. 2007;11(2):113-34.

9. Pastoral da Criança. Guia do líder da Pastoral da Criança: para países de língua portuguesa [internet]. Curitiba: Calgan; 2018. [Acesso em 22 abr. 2020]. Disponível em https://www.pastoraldacrianca.org.br/ images/materiaiseducativos/guia-do-lider-

2015-ed-18.pdf.

10. Queiroz SMPL, Moysés SJ, França BHS, Bisinelli JC, Moysés ST. Paths for promoting oral health: capacitation among leaders of the Children's Pastoral Mission of the Catholic Church in Brazil. Interface (Botucatu). 2010;14(34):619-32.

11. Essvein G, Baumgarten A, Rech RS, Hilgert JB, Neves M. Dental care for early childhood in Brazil: from the public policy to evidence. Rev Saúde Públ. 2019;53:15.

12. Mathur VP, Dhillon JK. Dental Caries: A disease which needs attention. Indian $\mathbf{J}$ Pediatr. 2018;85(3):202-6.

13. Mendes TDMC, Ferreira TLDS, Carvalho YDM, Silva LGD, Souza CMCDL, Andrade, FBD. Contribuições e desafios da integração ensino-serviço-comunidade. Texto Contexto Enferm. 2020;29: e20180333.

14. Siqueira SMC, Jesus VSD, Santos ENBD, Whitaker MCO, Sousa BVN, Camargo CLD. Atividades extensionistas, promoção da saúde e desenvolvimento sustentável: experiência de um grupo de pesquisa em enfermagem. Esc Anna Nery. 2017;21(1):e20170021.

15. Moimaz SAS, Bordin D, Gomes AM de P, Fadel CB, Garbin CAS, Saliba NA. Extensão universitária na ótica de acadêmicos: o agente fomentador das Diretrizes Curriculares Nacionais. Rev ABENO. 2015;15(4):45-54.

16. Brasil. Ministério da Educação. Parecer CNE/CES n.803/2018, de 05 de dezembro de 2018. Aprova Diretrizes Curriculares Nacionais do Curso de Graduação em Odontologia. Brasília, DF: Ministério da Educação; 2018.

17. Ferraresso LFOT, Codato LAB. Aprendizados e reflexões advindos de 
atividade extensionista de educação em saúde em Centros de Educação Infantil. Rev Ciênc Plural. 2021;7(2):132-48.

18. Silva FO da, Marques RM. Espaço escolar sob a visão das crianças: narrativas, percepções e representações. Ver Tempos Espaços Educ. 2020;13(32):1-19.

19. World Health Organization. The optimal duration of exclusive breastfeeding: a systematic review. Geneva: WHO; 2001.

20. Menezes RR de, Coelho AS, Lobo MRG. A importância da amamentação na formação de vínculos afetivos saudáveis entre mamãe/bebê. Rev Bol Inf Uni Soc- BIUS. 2019;12(5):1-15.

21. Ardic C, Usta O, Omar E, Y1ld1z C, Memis E. Efectos de las prácticas alimentarias durante la lactancia y de las características maternas en la obesidad infantil. Arch Argent Pediatr. 2019;117(1):26-33.

22. Carrascoza KC, Possobon $\mathrm{R}$ da $\mathrm{F}$, Ambrosano GMB, Costa Júnior ÁL, Moraes ABA. Fatores determinantes do uso de chupeta entre crianças participantes de programa de incentivo ao aleitamento materno. Rev CEFAC. 2014;16(2):582-91.

23. Sociedade Brasileira de Pediatria. Uso de chupeta em crianças amamentadas: prós e contras. Guia prático de atualização. Departamento Científico de Aleitamento Materno. 2017, n.3, 1-16.

24. Cabral MBBS, Mota ELA, Cangussu MCT, Vianna MIP. Situação de saúde bucal de crianças na primeira infância em creches de Salvador, Bahia. Rev Baiana Saúde Pública. 2017;41(3):595-613.

25. Paula BA, Freire-Maia J, Júnior PAM, Freire-Maia FB. Introdução precoce da sacarose está associada à presença de cárie dentária em bebês. Arq Odontol. 2019;55:e12.

26. Brasil. Ministério da Saúde. Guia alimentar para crianças brasileiras menores de 2 anos [Internet]. Brasília: Ministério da Saúde; 2019 [Acesso em 22 abr. 2020]. Disponível em http://189.28.128.100/dab/ docs/portaldab/publicacoes/guia_da_crian ca_2019.pdf.

27. Santili PGJ, Rocha Tonhom SF, Marin MJS. Educação em saúde: algumas reflexões sobre sua implementação pelas equipes da estratégia saúde da família. Rev Bras Promoç Saúde. 2017;29:102-10.

28. Codato LAB, Garanhani MLG, González AD. Percepções de profissionais sobre o aprendizado de estudantes de graduação na Atenção Básica. Physis. 2017;27(3):605-19.

29. Falkenberg MB, Mendes TPL, Moraes EP de, Souza EM de. Educação em saúde e educação na saúde: conceitos e implicações para a saúde coletiva. Ciênc. Saúde Colet. 2014;19(3):847-852.

30. Iglesias LM. Avaliação das ações educativa-preventivas em crianças para o controle da placa bacteriana oriundas de projetos sociais. São Paulo. Tese de doutorado - Universidade Paulista; 2018.

31. Emmi DT, Barroso RFF. A Biodiversidade Amazônica na promoção da saúde bucal: Elaboração de evidenciador de placa dental utilizando os corantes do açaí e urucum e a análise comparativa de sua eficácia em relação aos corantes sintéticos. Belém. Trabalho de Conclusão de Curso [Graduação em Odontologia] Universidade Federal do Pará; 2001.

32. Associação Paulista de Cirurgiões Dentistas da Saúde [internet]. Qual a melhor técnica para escovar os dentes? Um estudo intitulado análise dos métodos de escovação dentária recomendados por associações odontológicas. [Acesso em 10 jul. 2021]. Disponível em: http://www.apcdsaude.org.br/detNot.asp?id=1526\&moda $=\&$ 
contexto $=\&$ area $=008 \&$ evento $=$.

33. Brasil. Ministério da Saúde. Secretaria de Atenção à Saúde. Departamento de Atenção Básica. Saúde Bucal. Cadernos de Atenção Básica, n. 17 [Internet]. Brasília: Ministério da Saúde; 2006 [Acesso em 15 jul. 2021]. Disponível em: http://cfo.org.br/wpcontent/uploads/2009/10/cadernos_de_aten \%C3\%A7\%C3\%A30_b\%C3\%A1sica_sa\% C3\%BAde bucal.pdf.

34. Hanna LMO, Nogueira AJDS, Honda VYS. Percepção das gestantes sobre a atenção odontológica precoce nos bebês. RGO. 2007;55(3):271-4.

35. Cameron AC, Widmer RP, editores. Manual de odontopediatria [Internet]. Rio de Janeiro: Elsevier; 2012 [Acesso em 9 jul. 2021]. Disponível em: https:// docero.com.br/doc/n555v5.

36. Jagher AC, Ripplinger T, Pinto GS, Schardosim LR. Avaliação da utilização de dentifrício fluoretado em crianças. RFO. 2016;21(1):37-42.

37. Sociedade de Pediatria de São Paulo [homepage na internet]. Uso de pasta, fio dental, verniz de flúor e selante: dúvidas mais frequentes [Acesso em 3 jul. 2020]. Disponível em: https://www.spsp.org. br/2012/12/12/uso-de-pasta-fio-dentalverniz-de-fluor-e-selante-duvidas-maisfrequentes/.
38. Degrazia FW, Genari B. Guia para gestantes e mães de primeira viagem: tudo para sua saúde bucal e a de seu filho. Simplíssimo; 2021. [Acesso em 14 jul. 2021]. Disponível em: https://books.google.com.br/books? $\underline{\mathrm{hl}=\mathrm{pt}-\mathrm{BR} \& \mathrm{lr}=\& \mathrm{id}=\mathrm{D} 3 \mathrm{gUEAAAQBAJ} \& \mathrm{oi}}$ $=$ fnd $\& p g=P T 6 \& d q=$ guia + para + gestantes+e +m\%C3\%A3es+de+primeira+viagem+brun $\underline{a+g e n a r i \& o t s}=x 4 y c q S f S J I \&$ sig $=$ U_wRXG Fs7 fhofCZx7gp2Y3gvM\#v=onepage $\& \mathrm{q}=$ guia $\% 20$ para $\% 20$ gestantes $\% 20 \mathrm{e} \% 20 \mathrm{~m} \% \mathrm{C} 3$ $\%$ A3es\%20de\%20primeira\%20viagem $\% 20$ bruna $\% 20$ genari\&f=false.

39. Global Child Dental Fund [internet]. Guia de Saúde Oral Materno-Infantil [Acesso em 12 de jul. 2021]. Disponível em: https://www.sbp.com.br/fileadmin/user_upl oad/Guia-de-Saude_Oral-MaternoInfantil.pdf.

\section{Correspondência para:}

Lucas Fernando Oliveira Tomaz Ferraresso e-mail: lucas.fernando@uel.br Clínica Odontológica Universitária Rodovia Celso Garcia Cid, PR 445, Km 380, Campus Universitário 86044-766 Londrina/PR 